NBER WORKING PAPER SERIES

\title{
THE ENDOGENEITY OF THE OPTIMUM CURRENCY AREA CRITERIA
}

Jeffrey A. Frankel

Andrew K. Rose

NBER Working Paper 5700

\section{NATIONAL BUREAU OF ECONOMIC RESEARCH 1050 Massachusetts Avenue \\ Cambridge, MA 02138 \\ August 1996}

We thank: Shirish Gupta for research assistance, IIES and ECARE for hospitality during the course of writing this paper; Lars Calmfors, Barry Eichengreen, Harry Flam, Hans Genberg, Carl Hamilton, Jon Hassler, Rich Lyons, Jacques Melitz, Torsten Persson, Chris Pissarides, Lars Svensson, and seminar participants at IIES and the Swedish Government Commission's Public Hearing on EMU for comments; and the National Science Foundation for research support. A longer version of this paper with special emphasis on Sweden and EMU (entitled "Economic Structure and the Decision to Adopt a Common Currency") circulates as a background report for the Swedish Government Commission on EMU. This paper is part of NBER's research programs in International Finance and Macroeconomics and International Trade and Investment. Any opinions expressed are those of the authors and not those of the National Bureau of Economic Research.

(C) 1996 by Jeffrey A. Frankel and Andrew K. Rose. All rights reserved. Short sections of text, not to exceed two paragraphs, may be quoted without explicit permission provided that full credit, including (C) notice, is given to the source. 


\title{
THE ENDOGENEITY OF THE OPTIMUM CURRENCY AREA CRITERIA
}

\begin{abstract}
A country's suitability for entry into a currency union depends on a number of economic conditions. These include, inter alia, the intensity of trade with other potential members of the currency union, and the extent to which domestic business cycles are correlated with those of the other countries. But international trade patterns and international business cycle correlations are endogenous. This paper develops and investigates the relationship between the two phenomena. Using thirty years of data for twenty industrialized countries, we uncover a strong and striking empirical finding: countries with closer trade links tend to have more tightly correlated business cycles. It follows that countries are more likely to satisfy the criteria for entry into a currency union after taking steps toward economic integration than before.
\end{abstract}

Jeffrey A. Frankel

Economics Department

University of California

Berkeley, CA 94720-3880

and NBER

frankel@econ.berkeley.edu
Andrew K. Rose

Haas School of Business

University of California

Berkeley, CA 94720-1900

and NBER

arose@haas.berkeley.edu 


\section{The Endogeneity of the Optimum Currency Area Criteria}

\section{Introduction}

Countries considering whether to enter the proposed European Economic and Monetary Union (EMU) weigh the potential benefits of joining the currency union against the inevitable costs. Joining a currency union brings benefits such as a reduction in the transactions costs associated with trading goods and services between countries with different moneys. Countries with close international trade links would potentially benefit greatly from a common currency and are more likely to be members of an optimum currency area (OCA). Thus, the nature and extent of international trade is one criterion for EMU entry, or, more generally, membership in an OCA.

On the other hand, joining EMU brings costs. Cited most frequently is foregoing the possibility of dampening business cycle fluctuations through independent counter-cyclic monetary policy.' Countries with idiosyncratic business cycles give up a potentially important stabilizing tool if they join a currency union. Another criterion for EMU entry is therefore the cross-country correlation of business cycles. Countries with "symmetric" cycles are more likely to be members of an OCA. Succinctly, countries with tight international trade ties and positively correlated business cycles are more likely to join, and gain from EMU, ceteris paribus.

These topics have already been closely studied by economists. Estimates of the transactions costs that might be saved by EMU have been summarized by the Commission of the European Communities (1990). A number of economists, including Bayoumi and Eichengreen (1993a, 1993b, 1994, 1996), have analyzed the business cycles and shocks affecting different potential EMU members, so as to be able to quantify the potential importance of national

\footnotetext{
1 The cost of losing monetary independence may be low if labor is mobile among the members of the currency union, or if an effective international or intertemporal system of fiscal transfers exists. We do not focus explicitly on these issues in this paper, although the European Commission (1990) provides extensive references.
} 
monetary policy. Our aim in this paper is to link the two issues so as to make a simple point. We argue that a naïve examination of historical data gives a misleading picture of a country's suitability for entry into a currency union, since both criteria are endogenous. ${ }^{2}$

Entry into a currency union may significantly raise international trade linkages (and therefore the benefits foregone by not joining a currency union). More importantly, tighter international trade ties may significantly affect the nature of national business cycles. Countries that enter a currency union are likely to experience dramatically different business cycles than before. In part this will necessarily reflect changes in monetary policy; but in it will also be a result of closer international trade with the other members of the union. From a theoretical viewpoint, closer international trade could result in either tighter or looser correlations of national business cycles. Cycles could, in principle, become more idiosyncratic. Closer trade ties could result in countries becoming more specialized in the goods in which they have comparative advantage, as noted by e.g., Eichengreen (1992), Kenen (1969), and Krugman (1993). The countries might then be more sensitive to industry-specific shocks, resulting in more idiosyncratic business cycles. However, if demand shocks predominate, or there are important shocks which are common across countries - or intra-industry trade accounts for most trade - then business cycles may become more similar across countries when countries trade more. We believe the latter case to be the more realistic one, but consider the question to be open.

We test our view empirically, using a panel of bilateral trade and business cycle data spanning twenty industrialized countries over thirty years. The empirical results are strong and clear-cut. They indicate that closer international trade links result in more closely correlated business cycles across countries. This finding is interesting since a number of economists have

\footnotetext{
2 The European Commission (1990) has already recognized both of these phenomena For instance, on pll they state "...Elimination of exchange rate uncertainty and transactions costs ... are sure to yield gains in efficiency ...
} 
claimed the opposite.

Our findings lead to a number of conclusions on the prospects and desirability of EMU. Continued European trade liberalization can be expected to result in more tightly correlated European business cycles, making a common European currency both more likely and more desirable. Indeed, monetary union itself may lead to a further boost to trade integration and hence business cycle symmetry. Countries which join EMU, no matter what their motivation, may satisfy OCA criteria ex post even if they do not ex ante!

In part II of the paper, we provide a theoretical framework for our analysis, drawing heavily on the large literature on Optimum Currency Areas (OCAs). We next discuss the literature briefly, and present our empirical methodology and data set. Section V contains our actual empirical results, and section VI has a brief conclusion.

\section{Theoretical Framework}

Since Mundell (1961) first developed the concept of an optimum currency area, a vast literature has developed in the area. This literature includes classic contributions by McKinnon (1963) and Kenen (1969). Recent surveys are available in Tavlas (1992) and Bayoumi and Eichengreen (1996). Much of this literature focuses on four inter-relationships between the members of a potential OCA. They are: 1) the extent of trade;2) the similarity of the shocks and cycles; 3) the degree of labor mobility; and 4) the system of fiscal transfers (if any). The greater the linkages between the countries using any of the four criteria, the more suitable a common currency. 
Given the theoretical consensus in the area, it is natural that the OCA criteria have been applied extensively. For instance, when most researchers judge the suitability of different European countries for EMU, they examine the four criteria (or some subset) using European data, frequently using the United States as a benchmark for comparison.

Such a procedure may be untenable, since the OCA criteria are jointly endogenous. For instance, the suitability of European countries for EMU cannot be judged on the basis of historical data since the structure of these economies is likely to change in the event of EMU. As such, this paper is simply an application of the well-known "Lucas Critique". Without denying the importance of the third and fourth criteria, we focus on the first two OCA criteria.

\section{II.a The OCA Paradigm}

Countries that are highly integrated with each other, with respect to international trade in goods and services, are more likely to constitute an optimum currency area. Openness is one criterion for membership in an OCA since greater trade leads to greater savings in the transactions costs and risks associated with different currencies, as already noted. Further, the high marginal propensity to import associated with an open economy reduces output variability and the need for domestic monetary policy, since openness acts as an automatic stabilizer.

Of course, openness is not the only criterion for membership in a common currency area. Ever since Mundell (1961) it has been appreciated that the more highly correlated the business cycles are across member countries, the more appropriate a common currency. Only countries whose business cycles are imperfectly synchronized with others' could benefit from the potential stabilization afforded by a national monetary policy. ${ }^{3}$

\footnotetext{
${ }^{3}$ We take it for granted that monetary policy cannot permanently affect either a country's real income level or growth rate; hence our focus on business cycles.
} 
In Figure 1 we graph conceptually the extent of trade among members of a potential common currency area, against the correlation of their incomes. The OCA line is downwardsloping: the advantages of adopting a common currency depend positively on both trade integration and the degree to which business cycles are correlated internationally. Points high up and to the right represent groupings of countries that should share a common currency; the benefits outweigh the costs of lost monetary independence. Points down and to the left represent countries that should float individually, since monetary sovereignty outweighs the transactions cost savings of a common currency.

Can the degree of integration between potential members of a common currency area be considered independently of income correlation? Surely not, since the correlation of business cycles across countries depends on trade integration. Though it is often treated as a parameter, integration changes over time. European countries trade with each other more than in the past, and this trend may continue. It is driven in part by regional trade policy: such initiatives as the completion of the single market in 1992 and the expansion of the EU to 15 members. EMU itself may promote intra-European trade, if the effects of the exchange rate risk and transactions costs are important, as EMU proponents claim. Thus cyclic correlation is endogenous with respect to trade integration, while integration is also affected by policy.

Our hypothesis is that this relationship is positive: the more one country trades with others, the more highly correlated will be their business cycles. This is certainly the relationship pictured by the Commission of the European Communities (1990). But it is not universally accepted. Authors such as Eichengreen (1992), Kenen (1969), and Krugman (1993) have pointed out that as trade becomes more highly integrated, countries specialize more in production. They seem to expect that increased degree of specialization will reduce the international correlation of 
incomes, given sufficiently large supply shocks.

\section{II.b Further Analysis}

Ideally, we would use a general equilibrium model of international trade to derive testable hypotheses. Such a model would have to involve barriers to trade (either "natural," such as transportation costs, or "created" such as tariffs and non-tariff barriers), since our objective is to gauge the impact of reduced trade barriers on the international co-movements of business cycles. Because of the latter point, this model, unlike many models of international trade, would have to be stochastic with roles for both industry-specific and aggregate shocks. Further, it would have to involve both inter-sectoral trade (so as to be able to accommodate specialization) and intraindustry trade (since the effects on the latter of opening trade are thought to be large and different from those on inter-industry trade). ${ }^{4}$

Creating such a model from scratch is beyond the limited scope of this (chiefly empirical) paper. Our objective here is much more modest. We seek in this section merely to provide some intuition for the interplay between trade intensity and business cycles. We begin by expressing output as:

$$
\Delta y_{t}=\Sigma_{i} \alpha_{i} u_{i t}+v_{t}+g
$$

where: $\Delta y_{t}$ represents the growth rate of real output for the domestic country at time $t ; u_{i, t}$ is the sector-specific deviation of the growth rate of output in sector $i$ at time $t$ from the country's

\footnotetext{
${ }^{4}$ Ricci (1996) provides a theoretical analysis which contains many of these elements. His analysis focuses on the relationship between the exchange rate regime and firm location (with consequences for the extent of international trade). Using a static model which incorporates both inter-industry and intra-industry trade, he finds that flexible
} 
average growth rate at time $t, v_{i} ; \alpha_{i}$ is the weight of sector $i$ in total output $\left(\Sigma_{i} \alpha_{i}=1\right)$; and $g$ is the trend rate of output growth for the country. The analog for the foreign country is:

$$
\Delta \mathrm{y}_{\mathrm{t}}=\Sigma_{\mathrm{i}} \alpha_{\mathrm{i}}^{*} \mathrm{u}_{\mathrm{i}, \mathrm{t}}+\mathrm{v}_{\mathrm{t}}+\mathrm{g}^{*}
$$

where an asterisk denotes a foreign value, and we assume that the sector-specific shocks (but not necessarily the sector-specific output shares) are common across countries. Stockman (1988) provides one simple way to derive and use univariate output models like this in a standard neoclassical setting.

We assume that the $\left\{\mathrm{u}_{i, t}\right\}$ are distributed independently across both sector and time of each other, with sectoral variance $\sigma_{i}^{2}$. We further assume that the $\left\{v_{t}\right\}$ are distributed independently over time, independently of the sector-specific shocks. For simplicity, we also abstract from trend effects in the analysis which follows, though we return to the issue below.

The cross-country covariance of output is:

$$
\begin{aligned}
\operatorname{Cov}\left(\Delta y_{\mathrm{t}}, \Delta \mathrm{y}^{*} \mathrm{t}\right) & =\operatorname{Cov}\left(\Sigma_{\mathrm{i}} \alpha_{\mathrm{i}} \mathrm{u}_{\mathrm{i}, \mathrm{t}}, \Sigma_{\mathrm{i}} \alpha^{*} \mathrm{u}_{\mathrm{i}, \mathrm{i}}\right)+\operatorname{Cov}\left(\mathrm{v}_{\mathrm{t}}, \mathrm{v}^{*}{ }_{\mathrm{t}}\right) \\
& =\Sigma_{i} \alpha_{\mathrm{i}} \alpha^{*}{ }_{i} \sigma_{\mathrm{i}}^{2}+\sigma_{\mathrm{v}, v^{*}}
\end{aligned}
$$

where $\sigma_{\mathrm{v}, v^{*}}$ is the covariance between the country-specific aggregate shocks.

exchange rates induce specialization compared with fixed rates, since they automatically dampen the effects of industry-specific (and other) shocks. 
In our empirical analysis, we work with correlation coefficient estimates, that is the covariance adjusted for the country-specific volatility of aggregate income. The degree to which business cycles are correlated internationally rises or falls depends on how this covariance changes with increased integration. ${ }^{5}$ Increased integration may affect both terms; we consider them sequentially.

As noted by Eichengreen and Krugman, increased trade results in greater specialization if most trade is inter-industry. As countries tend to produce and export goods in which they have a comparative advantage, a negative cross-industry correlation between $\alpha_{i}$ and $\alpha^{*}{ }_{i}$ tends to develop; the covariance falls accordingly. If much trade is within rather than between industries, such specialization effects may be small. The latter sort of trade -- intra-industry - has attracted much attention of late and is commonly considered to account for a major share of international trade.

The covariance of the country-specific aggregate shocks may also be affected by increased integration. There are a number of potentially important channels. The spill-over of aggregate demand shocks will tend to raise the covariance, since e.g., an increase in public or private spending in one country tends to raise demand for both foreign and domestic output. This may not be the only channel. The presence of greater trade integration may also induce a more rapid spread of productivity shocks, raising the covariance (e.g., Coe and Helpman). Further, government-induced policy shocks may become more coordinated in the presence of increased integration.

It seems to us that closer international integration will tend to raise the covariance of country-specific demand shocks and aggregate productivity shocks. This tends to increase the

\footnotetext{
${ }^{5}$ Our data set shows no relationship between openness and activity volatility.
} 
international coherence of business cycles. On the other hand, integration tends to raise the degree of industrial specialization, leading to more asynchronous business cycles. The importance of this effect depends on the degree of specialization induced by integration, which may not be large if most trade is intra-industry rather than inter-industry. And the net effect on business cycle coherence depends on the relative variances of aggregate and industry-specific shocks. If the former are larger than the latter (as in e.g., Stockman (1988)), then we would expect closer trade integration to result in more synchronized business cycles.

Casual empiricism leads us to the view that integration results in more highly correlated national business cycles. However, the alternative view is defensible on theoretical grounds. The matter can only be resolved empirically. We now turn to that task.

\section{Related Results from the Literature}

A number of papers have examine the international correlation structure of business cycles. We review the relevant papers briefly.

Cohen and Wyplosz (1989) examined the correlation of output growth rates for Germany and France; Weber (1991) did so for other members of the European Community. Stockman (1988) decomposes cross-countries growth rates of industrial production for European countries into industry-specific and country-specific components. Bayoumi and Eichengreen (1993a,b,c, 1994) argue that these studies conflate information on the incidence of disturbances and on economies' responses. Accordingly, Bayoumi and Eichengreen use structural vector autoregressions to distinguish underlying aggregate demand and aggregate supply disturbances from the subsequent dynamic response. They use the results to find plausible groupings of countries for monetary union. We see little justification, however, for the assumption that supply 
disturbances are the only ones to which independent monetary policy may wish to respond.

De Grauwe and Vanhaverbeke (1993) find that "asymmetric" or idiosyncratic shocks tend to be more prevalent at the level of regions within a country than at the level of nations within Europe. This seems to support the view that increasing integration, may result in more idiosyncratic activity. However, De Grauwe and Vanhaverbeke use the standard deviation of the difference in percentage changes in income between the two regions instead of the correlation of percentage changes in income between two regions,. This may be a less useful measure of income links. There is every reason to think that the variance of income at the regional level is much higher than the variance of income at the national level. Since national income is the sum of regional income, some local variation is bound to wash out despite the presence of potentially high inter-regional correlations. ${ }^{6}$

Close in spirit to our view is a recent paper by Artis and Zhang (1995), which finds that most European countries' incomes were more highly correlated with the U.S. during 1961-79, but (with the exception of the UK) have become more highly correlated with Germany since joining the ERM?

All this work is subject to the Lucas Critique discussed above. Perhaps more importantly, no existing work, to the best of our knowledge, attempts to endogenize international business cycle correlations.

\section{Empirical Methodology}

\footnotetext{
6 If regional variances are larger than national variances, simple algebra can show that the variance of regional differences can appear larger than the variance of national differences, even though regional incomes are in fact more highly correlated than national variances.

7 Of course this may be the result of the loss of monetary independence, rather than of increased trade.
} 
In this section, we present some empirical evidence on the relationship between bilateral income correlations and bilateral trade intensity. The evidence is consistent with a strong positive effect of trade intensity on income correlations.

\section{IV.a Measuring Bilateral Trade Intensity and Business Cycle Correlations}

Our empirical analysis relies on measures of two key variables: bilateral trade intensity; and bilateral correlations of real economic activity. We discuss these in turn. ${ }^{8}$

We are interested in the bilateral intensity of international trade between two countries, $i$ and $j$ at a point in time $t$. We use three different proxies for bilateral trade intensity. The first uses export data exclusively; the second uses only imports, and the final (and preferred) measure uses both exports and imports:

$$
\begin{aligned}
& w_{\mathrm{ijt}}=\mathrm{X}_{\mathrm{ij} /} /\left(\mathrm{X}_{\mathrm{i} . \mathrm{t}}+\mathrm{X}_{\mathrm{j} . \mathrm{l}}\right) \\
& w^{i j t}=M_{i j l} /\left(M_{i, l}+M_{j . l}\right) \\
& w t_{i j t}=\left(X_{i j t}+M_{i j t}\right) /\left(X_{i, t}+X_{j . t}+M_{i, t}+M_{j, t}\right)
\end{aligned}
$$

where: $X_{i j t}$ denotes total nominal exports from country $i$ to country $j$ during period $t ; X_{i . t}$ denotes total global exports from country $\mathrm{i}$; and $\mathrm{M}$ denotes imports. (In practice we take natural logarithms of all three ratios.) We think of higher values of e.g., wt $\mathrm{tijt}_{\mathrm{t}}$ as indicating greater trade intensity between countries $i$ and $j$.

The bilateral trade data are taken from the International Monetary Fund's Direction of Trade data set. The data are annual and cover twenty-one industrial countries from 1959 through

8 The STATA 4.0 data set and programs are available for one year upon receipt of two formatted 3.5" diskettes and a selfaddressed, stamped mailer. 
There are a variety of problems associated with bilateral trade data (e.g., $X_{\mathrm{ijt}} \neq \mathrm{M}_{\mathrm{jit}}$ ). Our data measure actual trade intensity, which may understate the potential importance of trade. Further, from a theoretical point of view, it is unclear which set of weights is optimal; some countries may have specialized exports or imports. Thus we conduct our tests with all three measures of trade intensity. Reassuringly, our answers appear to be insensitive to the exact way that we measure trade intensity. This is unsurprising, as the three different measures are highly positively inter-correlated. Figure 2 provides scatter-plots of each measure of trade intensity graphed against the others; non-parametric data smoothers are also provided to "connect the dots".

Our other important variable is the bilateral correlation between real activity in country $i$ and country $j$ at time $t$. Again, it is difficult to figure out the optimal single empirical analog to the theoretical concept. We therefore use a variety of different proxies.

We use four different measures of real economic activity: the first pair taken from the International Monetary Fund's International Financial Statistics; the other two from the OECD's Main Economic Indicators. In particular, we use: real GDP (typically IFS line 99); an index of industrial production (line 66); total employment (OECD mnemonic "et"); and the unemployment rate ("unr"). All the data are quarterly, covering (with gaps) the same sample of countries and years as the trade data.

We transform our variables in two different ways. First, we take natural logarithms of each variable except the unemployment rate. Second, we de-trend the variables so as to focus on business cycle fluctuations. Given the importance of different de-trending procedures, and the

9 The countries are: Australia; Austria; Belgium; Canada; Denmark; Finland; France; Germany; Greece; Ireland; Italy; Japan; Norway; Netherlands; New Zealand; Portugal; Spain; Sweden; Switzerland; the UK; and the US. In 
lack of consensus about optimal de-trending techniques, we employ four different de-trending methodologies.

First, we take simple fourth-differences of the (logs of the) variables (i.e., we subtract the fourth lag of e.g., real GDP from the current value), multiplying by 100 (so that the resulting variable can be interpreted as a growth rate). Second, we de-trend the variables by examining the residual from a regression of the variable on a linear time trend, a quadratic time trend, and three quarterly dummies. Third, we de-trend the variables using the well-known Hodrick-Prescott ("HP") filter (using the traditional smoothing parameter of 1600). Finally, we apply the HP filter to the residual of a regression of the variable on a constant and quarterly dummies.

We have also constructed a fifth transformation of our dependent variable. This is similar to our second variant in that we de-trend the variables by examining the residual from a regression of the variable on a set of controls. But we add a control which is meant to account for the dependency of the economy to imported oil price shocks. In particular, we take the real price of oil (the price of oil in dollars per barrel, divided by the CPI for industrial countries), and multiply it by net exports of fuel, expressed as a percentage of nominal GDP. This variable, meant to measure the degree of dependency on imported oil, is then added to our other control variables including linear and quadratic time trends, and quarterly dummies.

After appropriately transforming our variables, we are able to compute bilateral correlations for real activity. These correlations are estimated (for a given concept of real economic activity), between two countries over a given span of time. Thus, for instance, we estimate the correlation between real GDP de-trended with the HP filter for two countries $i$ and $j$ over the first part of our sample period. We begin by splitting our sample into four equally-size parts: the beginning of the sample through 1967Q3; 1967Q4 through 1976Q2; 1976Q3 through 
1985Q1; and 1985Q2 through the end of the sample. Since we have twenty-one countries, we are thus left with a sample size of 840 observations; 210 bilateral country-pair correlations $[=(21 \times 20) / 2]$, with four observations (over different time periods) per country-pair.

While our three measures of trade intensity are similar to one another, the same is not true of our sixteen measures of business cycle correlations. Both the measure of economic activity (GDP/industrial production, etc.) and the de-trending technique matter (though all sixteen measures of bilateral activity correlation are positively correlated with each other). Figure 3 graphs different of business cycle correlations against each other, holding the de-trending method constant (at fourth-differencing) but allowing the underlying activity measure to vary. Figure 4 is an analog which varies the de-trending technique but only portrays real GDP. Since the international business cycle correlations are so imperfectly related to one another, we check the sensitivity of our results extensively.

\section{IV.b Econometric Methodology}

The regressions we estimate take the form:

$$
\operatorname{Corr}(v, s)_{i, j, \tau}=\alpha+\beta \operatorname{Trade}(w)_{i, j, \tau}+\varepsilon_{i, j, \tau}
$$

$\operatorname{Corr}(\mathrm{v}, \mathrm{s})_{\mathrm{i}, \mathrm{j}, \mathrm{d}}$ denotes the correlation between country $i$ and country $j$ over time span $\tau$ for activity concept $v$ (corresponding to: real GDP (denoted " $y$ "); industrial production (i); employment (e); or the unemployment rate (u)), de-trended with method s (corresponding to: fourth-differencing (d); quadratic de-trending (t); HP-filtering (h); HP-filtering on the SA residual (s); or quadratic de-trending with the oil control (o)). Trade(w) $)_{i, j, r}$ denotes the natural logarithm of the average 
bilateral trade intensity between country $\mathrm{i}$ and country $\mathrm{j}$ over time span $\tau$ using trade intensity concept $w$ (corresponding to: export weights (x); import weights (m); or total trade weights (t)). Finally, $\varepsilon_{\mathrm{i}, \mathrm{j}, \mathrm{r}}$ represents the myriad influences on bilateral real activity correlations above and beyond the influences of international trade, and $\alpha$ and $\beta$ are the regression coefficients to be estimated.

We have sixteen versions of the regressand (as we consider four activity concepts and four de-trending methods) and three versions of the regressor (since we have three sets of trade weights). We estimate all 48 versions of our regression to check results for robustness.

The object of interest to us is the slope coefficient $\beta$. We are interested in both the sign and the size of the coefficient. The sign of the slope tells us whether the Eichengreen-Krugman specialization effect dominates (in which case we would expect a negative $\beta$, since more intense trading relations would be expect to lead to more idiosyncratic business cycles and hence a lower correlations of economic activity) or the expected traditional effect prevails (in which case $\beta$ would be expected to be positive). The size of the coefficient allows us to quantify the economic importance of this effect.

A simple OLS regression of bilateral activity income correlations on trade intensity may be inappropriate. Countries are likely deliberately to link their currencies to those of some of their most important trading partners, in order to capture gains associated with greater exchange rate stability. In doing so, they lose the ability to set monetary policy independently of those neighbors. The fact that their monetary policy will be closely tied to that of their neighbors could result in an observed positive association between trade links and income links. In other words, the association could be the result of countries' application of the OCA criterion, rather than an aspect of economic structure that is invariant to exchange rate regimes. 
To identify the effect of bilateral trade patterns on income correlations in such circumstances, we need exogenous determinants of bilateral trade patterns. Such determinants could be used as instrumental variables to produce consistent estimates of $\beta$. Our preferred set of instrumental variables includes the most basic variables of the well-known "gravity" model of bilateral trade: distance between the pair of countries in question, and dummy variables for common border or language. (We examine our "first-stage" instrument equations explicitly below. $)^{10}$

Parenthetically, estimation of the standard error for $\beta$ is potentially complicated. Our observations may not be independent; the e.g., French-Belgian observation for the first quarter of the sample may depend on either the French-Belgian observation for the second quarter, or the French-Dutch observation for the first quarter (or both). We ignore such potential dependencies in computing our covariance matrices, and instead try simply not to take their precise size too seriously. It turns out there is no need to do so, but this is a possible extension for future research."

\section{Empirical Results}

We begin our analysis with simple ordinary least squares. Consistent with our priors, estimation with instrumental variables turns out to deliver the same message even more strongly.

\section{V.a OLS Work}

Ordinary least squares (OLS) estimates of $\beta$ are tabulated in Table 1. The estimates, along with their standard errors, are presented in three columns, corresponding to the three different

${ }^{10}$ Instrumental variable estimation is also appropriate since the regressors are measured with error.

11 The data set reveals few signs of such dependency. White covariance matrices are very similar to traditional ones; non-parametric tests for dependencies across periods reveal no trends; boot-strapping our standard errors results in very similar standard error estimates. Parenthetically, our IV standard errors should be consistent in the 
measures of bilateral trade intensity. For each measure, sixteen estimates (four measures of economic activity each de-trended in four different ways) are presented in the rows.

The estimates indicate that a closer trade linkage between two countries is strongly and consistently associated with more tightly correlated economic activity between the two countries. The size of this effect depends on the exact measure of economic activity (as is expected), but does not depend very sensitively on the exact method of de-trending the data or the measure of bilateral trade intensity. Parenthetically, the adjustment for the oil price reduces the size of the coefficients slightly, although they remain positive and significant.

We have checked these results in a number of different ways, and they seem to be robust. For instance, a consistently positive estimate of $\beta$ appears whether or not the trade intensity measure is transformed by natural logarithms, and whether or not the observations are weighted by country size. More importantly, the results do not appear to be very sensitive to the exact sample chosen. The data from the last quarter of the sample show more evidence of a strongly positive estimate of $\beta$ than does that from the first quarter, but the exact choice of countries does not matter. We have also tested for the importance of important non-linearities in the relationship between trade intensity and activity correlations by estimating the equation with a non-parametric data smoother (similar to locally weighted regression but without neighborhood weighting); the non-linear effects are typically statistically insignificant and the strong positive effect of trade intensity on business cycle correlations is not affected. Adding either time-specific or countryspecific "fixed effect" controls (or both) also does not affect the sign or statistical significance of $\beta$. Finally, we have split our data set into two sub-periods across time (instead of four), and reestimated our equations. The resulting point-estimates of $\beta$ remain quite similar to those recorded in Table 1. 
The issue of simultaneous causation is potentially serious, since integration is itself endogenous. For this reason, we take instrumental variable (IV) estimates of $\beta$ more seriously than our OLS estimates. We use three instrumental variables: the natural logarithm of the distance between the business centers of the relevant pair of countries; a dummy variable for geographic adjacency; and a dummy variable which indicates if the pair of countries share a common language. Each of these variables is expected to be correlated with bilateral trade intensity, but can reasonably be expected to be unaffected by other conditions which affect the bilateral correlation of economic activity.

Direct evidence on the "first-stage" linear projections of (the natural logarithm of) bilateral period-average trade intensity on our three favored instrumental variables is presented in Table 2 . Distance (more precisely, the natural log thereof) is strongly negatively associated with trade intensity, as predicted by standard "gravity" models of international trade. Countries that share either a common border or a common language also have significantly more trade than others. The first-stage equations appear to fit relatively well.

Also included in Table 2 is a minor perturbation to our standard first-stage equation, namely the "default equation", augmented by a variable registering membership in a regional trade agreement. There are two relevant agreements: 1) the US/Canada FTA, and its successor, NAFTA; and 2) the EEC/EC. ${ }^{12}$ Membership in a regional trading agreement is strongly associated with more intense international trade in both an economic and statistical sense. Entry into a regional trade agreement appears to raise bilateral trade intensity by almost $50 \%$ (although further effects may also appear later on). While the variable appears to be approximately orthogonal to our three default instrumental variables, we do not use it as one of our default

\footnotetext{
12 We compute this variable by taking a pair-specific indicator variable (e.g., unity for UK/France in 1975, zero for the US/Japan in 1975) and estimating sub-period averages over time (e.g., the sub-period for the last quarter of the
} 
instrumental variables since it is potentially associated with tighter income correlations directly (e.g., through exchange rate arrangements; there is a high correlation between EC and EMS membership). Happily, our $\beta$ estimates are insensitive to inclusion or exclusion of the extra instrumental variable.

\section{V.b Instrumental Variable Estimation}

Instrumental variable estimates of $\beta$ (estimated with our three default instrumental variables) are tabulated in Table 3, which is a direct analog to Table 1. As expected, the results are consistent with the OLS results of Table 1, but they are somewhat stronger in both economic and statistical significance. The effect of greater intensity of international trade on the correlation of economic activity remains strongly positive and statistically significant, but is larger than the simple OLS estimates indicate (though we try not to interpret the t-statistics too literally, given the potential problems of cross-sectional or inter-temporal dependency). The oil-adjusted results are now slightly large than the other coefficients.

As with the OLS results, our IV estimates of $\beta$ are robust to a wide range of perturbations to our basic econometric methodology. We have performed all the experiments mentioned in conjunction with Table 1 without disturbing our central results. We have also changed the list of instrumental variables in a number of different ways without changing our results. For instance, adding dummy variables for membership in GATT or regional trade arrangements as extra instrumental variables does not change our results, as does adding country population and output.

\section{V.c More Sensitivity Analysis}

sample is non-zero for all EC-Spanish observations but the observations are not unity since Spain was not in the EC for the entire sub-sample; earlier Spanish observations are all zero). 
We have augmented our relationship by adding a dummy variable that is unity if the two countries shared a bilateral fixed exchange rate throughout the sample. This is an important test. The Bayoumi-Eichengreen view is that the high correlation among European incomes is a result not of trade links, but of Europeans' decision to relinquish monetary independence vis-à-vis their neighbors. If this is correct, putting the exchange regime variable explicitly on the right-hand side should show the effect, and the apparent effect of the trade and geography variables should disappear. Instead, the addition of this exchange rate variable does not significantly alter $\beta$. The actual estimates are provided in Table 4, which is an analog of Table 3 (with the same instrumental variables) when the equation is augmented by an indicator variable which is unity if the pair of countries maintained a mutually fixed exchange rate during the relevant sample period. For simplicity, only the results with total trade weights are reported. The positive $\beta$ coefficient still appears quite strong; indeed its sign and magnitude is essentially unchanged from Table 3. By way of contrast, the effect of a fixed exchange rate regime per se is not well determined. The coefficients vary in sign and magnitude depending on the exact measure of economic activity and de-trending method used to compute the bilateral activity correlation. ${ }^{13}$

Global oil price shocks are thought to be a major source of positively correlated business cycles, regardless of the exchange rate regime. We have performed a direct check for the importance of oil price shocks by augmenting our relationship with a variable meant to measure the degree of dependency on imported oil. The oil shock variable (the same used to adjust the oiladjusted regressands tabulated in Tables 1 and 3) is the product of two variables: the real price of oil (the price of oil in dollars per barrel, divided by the CPI for industrial countries), and net exports of fuel, expressed as a percentage of nominal GDP. We add the oil shock variable to our

\footnotetext{
${ }^{13}$ Results are not changed substantively if the actual bilateral exchange rate volatility is substituted for our indicator variable.
} 
default regression and estimate the coefficients with instrumental variables. The results are presented in Table 5. There are two sets of columns. The second is a minor perturbation, in that the extra regressor is the percentage change of the real oil price multiplied by next exports of fuel. Again, as in Table 4, the same instrumental variables as in Table 3 are used, and for simplicity, only the results with total trade weights are reported.

The positive $\beta$ coefficient still appears quite strong; indeed its sign and magnitude is essentially unchanged from Tables 3 and 4 . By way of contrast, the effect of oil price dependency is not firmly established. The coefficients vary in sign and magnitude when the level of the oil price is used. When the percentage change of the oil price is used, the oil price regressor has a consistently positive (though not always significant) coefficient. But the durable sign and significance of $\beta$ is unaffected.

\section{A Conclusion}

In this paper we have considered the relationship between two of the criteria used to determine whether a country is a member of an optimum currency area. From a theoretical viewpoint, the effect of increased trade integration on the cross-country correlation of business cycle activity is ambiguous. Reduced trade barriers can result in increased industrial specialization by country and therefore more asynchronous business cycles resulting from industry-specific shocks. On the other hand, increased integration may result in more highly correlated business cycles because of demand shocks or intra-industry trade.

This ambiguity is theoretical rather than empirical. Using a panel of thirty years of data from twenty industrialized countries, we find a strong positive relationship between the degree of bilateral trade intensity and the cross-country bilateral correlation of business cycle activity. That 
is, greater integration historically has resulted in more highly synchronized cycles.

The endogenous nature of the relationship between various OCA criteria is a straightforward application of the celebrated Lucas Critique. Still, it has considerable relevance for the current debate on Economic and Monetary Union in Europe. For instance, some countries may appear, on the basis of historical data, to be poor candidates for EMU entry. But EMU entry per se, for whatever reason, may provide a substantial impetus for trade expansion; this in turn may result in more highly correlated business cycles. That is, a country is more likely to satisfy the criteria for entry into a currency union ex post than ex ante. 
Table 1: OLS Estimates of $\beta$

(Effect of Trade Intensity on Income Correlation)

\begin{tabular}{|l|l|c|c|c|}
\hline Activity & De-Trending & Total Trade Weights & Import Weights & Export Weights \\
\hline GDP & Differencing & $7.1(.88)$ & $6.2(.79)$ & $6.7(.85)$ \\
\hline Ind Prod & Differencing & $6.9(.95)$ & $5.5(.83)$ & $6.9(.95)$ \\
\hline Employ & Differencing & $5.7(1.1)$ & $4.8(1.0)$ & $5.3(1.1)$ \\
\hline Unemp & Differencing & $3.3(.97)$ & $2.5(.87)$ & $3.1(.95)$ \\
\hline GDP & Quadratic & $7.2(1.1)$ & $6.3(.99)$ & $6.4(1.1)$ \\
\hline Ind Prod & Quadratic & $8.3(1.2)$ & $7.2(1.0)$ & $7.6(1.2)$ \\
\hline Employ & Quadratic & $6.2(1.4)$ & $6.1(1.3)$ & $4.8(1.5)$ \\
\hline Unemp & Quadratic & $7.0(1.4)$ & $6.1(1.3)$ & $6.4(1.5)$ \\
\hline GDP & HP-filter & $5.7(.92)$ & $4.2(.85)$ & $5.9(.88)$ \\
\hline Ind Prod & HP-filter & $5.6(1.0)$ & $4.5(.88)$ & $5.5(1.0)$ \\
\hline Employ & HP-filter & $6.6(1.1)$ & $5.7(.99)$ & $6.2(1.0)$ \\
\hline Unemp & HP-filter & $3.4(1.1)$ & $2.6(.95)$ & $3.2(1.0)$ \\
\hline GDP & HP-SA & $4.8(.84)$ & $3.9(.78)$ & $4.7(.81)$ \\
\hline Ind Prod & HP-SA & $4.9(.94)$ & $3.9(.81)$ & $4.8(.94)$ \\
\hline Employ & HP-SA & $6.5(1.0)$ & $5.7(.92)$ & $5.9(.94)$ \\
\hline Unemp & HP-SA & $3.2(1.0)$ & $2.4(.94)$ & $5.9(.98)$ \\
\hline GDP & Oil Adjusted & $4.7(1.2)$ & $3.8(1.1)$ & $4.7(1.2)$ \\
\hline Ind Prod & Oil Adjusted & $6.3(1.3)$ & $5.3(1.1)$ & $5.9(1.3)$ \\
\hline Employ & Oil Adjusted & $7.9(1.5)$ & $6.5(1.4)$ & $7.6(1.4)$ \\
\hline Unemp & Oil Adjusted & $4.7(1.5)$ & $4.3(1.3)$ & $4.1(1.4)$ \\
\hline
\end{tabular}

OLS estimate of $\beta$ (multiplied by 100) from

$$
\operatorname{Corr}(v, s)_{i, j, \tau}=\alpha+\beta \operatorname{Trade}(w)_{i, j, \imath}+\varepsilon_{i, j, r}
$$

Huber-White heteroskedasticity consistent standard errors in parentheses. Intercepts not reported.

Bilateral quarterly data from 21 industrialized countries, 1959 through 1993 split into four sub-periods.

Maximum sample size $\mathbf{=} 840$. 
Table 2: First-Stage Estimates

(Determinants of Bilateral Trade)

\begin{tabular}{|l|c|c|c|c|c|c|}
\hline & $\begin{array}{c}\text { Total } \\
\text { Trade } \\
\text { Weights }\end{array}$ & $\begin{array}{c}\text { Total } \\
\text { Trade } \\
\text { Weights }\end{array}$ & $\begin{array}{c}\text { Import } \\
\text { Weights }\end{array}$ & $\begin{array}{c}\text { Import } \\
\text { Weights }\end{array}$ & $\begin{array}{c}\text { Export } \\
\text { Weights }\end{array}$ & $\begin{array}{c}\text { Export } \\
\text { Weights }\end{array}$ \\
\hline Log of & -.45 & -.40 & -.52 & -.48 & -.43 & -.37 \\
Distance & $(.03)$ & $(.03)$ & $(.03)$ & $(.04)$ & $(.04)$ & $(.04)$ \\
\hline Adjacency & 1.03 & 1.01 & .83 & .81 & 1.21 & 1.19 \\
Dummy & $(.14)$ & $(.14)$ & $(.14)$ & $(.14)$ & $(.16)$ & $(.16)$ \\
\hline Common & .51 & .51 & .58 & .58 & .48 & .48 \\
Language & $(.11)$ & $(.11)$ & $(.11)$ & $(.11)$ & $(.13)$ & $(.13)$ \\
\hline Regional & & .44 & & .35 & & .54 \\
Trade & & $(.11)$ & & $(.12)$ & & $(.13)$ \\
Member & & & & & & \\
\hline N & 840 & 840 & 839 & 839 & 840 & 840 \\
\hline RMSE & .98 & .97 & 1.01 & 1.01 & 1.14 & 1.13 \\
\hline $\mathbf{R}^{2}$ & .39 & .40 & .40 & .40 & .33 & .34 \\
\hline
\end{tabular}

OLS estimates from

Trade $(w) i, j, \tau=\varphi 0+\varphi \operatorname{lLog}($ Distance) $i, j+\varphi 2$ Adjacent $i, j+\varphi 3$ Language $i, j+\varphi 4$ Regional $i, j, \tau+v i, j, \tau$.

Standard errors in parentheses. Intercepts not reported.

Bilateral quarterly data from 21 industrialized countries, 1959 through 1993 split into four sub-periods.

Maximum sample size $=840$. 
Table 3: IV Estimates of $\beta$

(Effect of Trade Intensity on Income Correlation)

\begin{tabular}{|l|l|c|c|c|}
\hline Activity & De-Trending & Total Trade Weights & Import Weights & Export Weights \\
\hline GDP & Differencing & $10.3(1.5)$ & $10.2(1.4)$ & $9.7(1.4)$ \\
\hline Ind Prod & Differencing & $10.1(1.5)$ & $9.8(1.5)$ & $9.8(1.5)$ \\
\hline Employ & Differencing & $8.6(1.8)$ & $8.4(1.8)$ & $8.2(1.8)$ \\
\hline Unemp & Differencing & $7.8(1.6)$ & $7.6(1.6)$ & $7.5(1.6)$ \\
\hline GDP & Quadratic & $11.3(1.9)$ & $11.1(1.9)$ & $10.7(1.8)$ \\
\hline Ind Prod & Quadratic & $9.3(2.1)$ & $9.0(2.0)$ & $9.0(2.0)$ \\
\hline Employ & Quadratic & $8.6(2.5)$ & $\mathbf{8 . 6 ( 2 . 4 )}$ & $7.9(2.4)$ \\
\hline Unemp & Quadratic & $10.8(2.4)$ & $10.5(2.4)$ & $10.6(2.3)$ \\
\hline GDP & HP-filter & $8.6(1.5)$ & $8.4(1.5)$ & $8.2(1.4)$ \\
\hline Ind Prod & HP-filter & $9.8(1.7)$ & $9.4(1.6)$ & $9.4(1.6)$ \\
\hline Employ & HP-filter & $10.1(1.8)$ & $9.8(1.8)$ & $9.7(1.8)$ \\
\hline Unemp & HP-filter & $7.8(1.7)$ & $7.5(1.7)$ & $7.6(1.6)$ \\
\hline GDP & HP-SA & $7.3(1.5)$ & $7.2(1.4)$ & $6.9(1.4)$ \\
\hline Ind Prod & HP-SA & $9.1(1.5)$ & $8.7(1.5)$ & $\mathbf{8 . 8 ( 1 . 5 )}$ \\
\hline Employ & HP-SA & $8.6(1.7)$ & $8.4(1.7)$ & $\mathbf{8 . 2 ( 1 . 7 )}$ \\
\hline Unemp & HP-SA & $8.1(1.7)$ & $7.8(1.7)$ & $\mathbf{7 . 8 ( 1 . 6 )}$ \\
\hline GDP & Oil Adjusted & $14.3(2.0)$ & $13.9(2.0)$ & $13.8(1.9)$ \\
\hline Ind Prod & Oil Adjusted & $14.0(2.2)$ & $13.5(2.1)$ & $13.6(2.1)$ \\
\hline Employ & Oil Adjusted & $13.7(2.4)$ & $13.4(2.4)$ & $12.9(2.3)$ \\
\hline Unemp & Oil Adjusted & $8.4(2.4)$ & $8.1(2.4)$ & $\mathbf{8 . 3 ( 2 . 3 )}$ \\
\hline
\end{tabular}

IV estimate of $\beta$ (multiplied by 100 ) from

$$
\operatorname{Corr}(v, s) i, j, \tau=\alpha+\beta \operatorname{Trade}(w) i, j, \tau+\varepsilon i, j, \tau .
$$

Instrumental Variables for trade intensity are: 1) log of distance; 2) dummy variable for common border, and 3) dummy variable for common language.

Standard errors in parentheses. Intercepts not reported. Bilateral quarterly data from 21 industrialized countries, 1959 through 1993 split into four sub-periods. Maximum sample size $=840$. 
Table 4: IV Estimates of $\beta$ and $\gamma$ (Effect of Fixed Rate Regime)

(Total Trade Weights)

\begin{tabular}{|l|l|c|c|}
\hline Activity & De-Trending & $\beta$ & $\gamma$ \\
\hline GDP & Differencing & $11.5(1.5)$ & $-13.0(2.9)$ \\
\hline Ind Prod & Differencing & $10.7(1.6)$ & $-5.1(2.9)$ \\
\hline Employ & Differencing & $8.9(1.9)$ & $-2.7(3.6)$ \\
\hline Unemp & Differencing & $7.3(1.7)$ & $5.1(3.2)$ \\
\hline GDP & Quadratic & $12.6(2.0)$ & $-15.2(3.7)$ \\
\hline Ind Prod & Quadratic & $11.3(2.2)$ & $-17.2(3.9)$ \\
\hline Employ & Quadratic & $9.4(2.6)$ & $-6.8(4.9)$ \\
\hline Unemp & Quadratic & $12.1(2.5)$ & $-13.2(4.8)$ \\
\hline GDP & HP-filter & $8.6(1.6)$ & $.0(3.0)$ \\
\hline Ind Prod & HP-filter & $10.8(1.7)$ & $-8.7(3.1)$ \\
\hline Employ & HP-filter & $10.4(1.9)$ & $-1.7(3.6)$ \\
\hline Unemp & HP-filter & $7.7(1.8)$ & $1.1(3.4)$ \\
\hline GDP & HP-SA & $6.5(1.5)$ & $10.8(2.8)$ \\
\hline Ind Prod & HP-SA & $9.9(1.6)$ & $-7.1(2.9)$ \\
\hline Employ & HP-SA & $\mathbf{8 . 6 ( 1 . 8 )}$ & $.5(3.4)$ \\
\hline Unemp & HP-SA & $7.6(1.8)$ & $4.7(3.3)$ \\
\hline
\end{tabular}

IV estimates of $\beta$ and $\gamma$ (multiplied by 100) from

$$
\operatorname{Corr}(v, s) i, j, \tau=\alpha+\beta \operatorname{Trade}(w) i, j, \tau+\gamma F L X i, j, \tau+\varepsilon i, j, \tau,
$$

where FIXi,,$\tau$ is the (period-average of a) dummy variable which is unity if $i$ and $j$ had a mutually fixed exchange rate during the period.

Instrumental Variables for trade intensity are: 1) log of distance; 2) dummy variable for common border, and 3) dummy variable for common language.

Standard errors in parentheses. Intercepts not reported.

Bilateral quarterly data from 21 industrialized countries, 1959 through 1993 split into four sub-periods.

Maximum sample size $\mathbf{=} \mathbf{8 4 0}$. 
Table 5: IV Estimates of $\beta$ and $\delta$ (Effect of Oil Price Shock)

(Total Trade Weights)

Price of Oil

Change in Oil Price

\begin{tabular}{|l|l|c|c|c|c|}
\hline Activity & De-Trending & $\boldsymbol{\beta}$ & $\delta$ & $\beta$ & $\delta$ \\
\hline GDP & Differencing & $10.3(1.5)$ & $.4(.5)$ & $9.8(1.4)$ & $6.2(1.1)$ \\
\hline Ind Prod & Differencing & $10.1(1.5)$ & $.8(.5)$ & $9.0(1.4)$ & $9.3(1.1)$ \\
\hline Employ & Differencing & $8.6(1.8)$ & $-.8(.6)$ & $8.4(1.8)$ & $2.5(1.4)$ \\
\hline Unemp & Differencing & $7.9(1.6)$ & $-2.5(.6)$ & $7.3(1.6)$ & $5.5(1.2)$ \\
\hline GDP & Quadratic & $11.2(1.9)$ & $2.5(.7)$ & $10.9(1.9)$ & $4.6(1.5)$ \\
\hline Ind Prod & Quadratic & $9.2(2.1)$ & $6.5(1.8)$ & $8.6(2.1)$ & $6.2(1.6)$ \\
\hline Employ & Quadratic & $\mathbf{8 . 6 ( 2 . 5 )}$ & $-.6(.8)$ & $8.5(2.5)$ & $.7(1.9)$ \\
\hline Unemp & Quadratic & $10.8(2.4)$ & $.5(.8)$ & $10.3(2.4)$ & $6.2(1.9)$ \\
\hline GDP & HP-filter & $8.6(1.5)$ & $.2(.5)$ & $8.2(1.5)$ & $4.6(1.2)$ \\
\hline Ind Prod & HP-filter & $9.7(1.6)$ & $4.3(1.5)$ & $8.7(1.6)$ & $9.2(1.2)$ \\
\hline Employ & HP-filter & $10.1(1.8)$ & $-1.0(.6)$ & $9.8(1.8)$ & $3.3(1.4)$ \\
\hline Unemp & HP-filter & $7.8(1.7)$ & $-.5(.6)$ & $7.3(1.7)$ & $5.6(1.3)$ \\
\hline GDP & HP-SA & $7.3(1.4)$ & $-.4(.5)$ & $6.9(1.4)$ & $4.6(1.1)$ \\
\hline Ind Prod & HP-SA & $9.0(1.5)$ & $4.2(1.3)$ & $8.2(1.4)$ & $7.3(1.1)$ \\
\hline Employ & HP-SA & $\mathbf{8 . 6 ( 1 . 7 )}$ & $-1.3(.6)$ & $\mathbf{8 . 4 ( 1 . 7 )}$ & $1.9(1.3)$ \\
\hline Unemp & HP-SA & $\mathbf{8 . 1 ( 1 . 7 )}$ & $-.6(.6)$ & $7.6(1.7)$ & $5.1(1.3)$ \\
\hline & & & & & \\
\hline
\end{tabular}

IV estimates of $\beta$ and $\gamma$ (multiplied by 100) from

$$
\operatorname{Corr}(v, s) i, j, \tau=\alpha+\beta \operatorname{Trade}(w) i, j, \tau+\delta\left(P_{1} L^{*}\{[(X F u e l-M F u e l) / Y] i[(X F u e l-M F u e l) / Y] j\}\right) \tau+\varepsilon i, j, \tau,
$$

where (POIL* $\{[$ XFuel-MFuel)/Y $] \mathrm{i}[(\mathrm{XFuel}-\mathrm{MFuel}) / \mathrm{Y}] \mathrm{j}\}) \tau$ is the (period-average of the product of the nominal price of oil (in $\$ / b b l$, deflated by the global CPI), net fuel exports normalized by nominal GDP in country $i$, and the latter variable for country $j$.

Instrumental Variables for trade intensity are : 1) log of distance; 2) dummy variable for common border; and 3) dummy variable for common language.

Standard errors in parentheses. Intercepts not reported.

Bilateral quarterly data from 21 industrialized countries, 1959 through 1993 split into four sub-periods.

Maximum sample size $=\mathbf{8 4 0}$. 


\section{References}

Artis, Michael, and Wenda Zhang, 1995, "International Business Cycles and the ERM: Is There a European Business Cycle?" CEPR Discussion Paper No. 1191, August.

Bayoumi, Tamim, and Barry Eichengreen, 1993a, "Shocking Aspects of European Monetary Unification," in F. Giavazzi and F. Torres, eds., The Transition to Economic and Monetary Union in Europe, Cambridge University Press, New York.

Bayoumi, Tamim, and Barry Eichengreen, 1993b, "Is There A Conflict Between EC Enlargement and European Monetary Unification," Greek Economic Review 15, no. 1, Autumn, 131-154.

Bayoumi, Tamim, and Barry Eichengreen, 1993c, "Monetary and Exchange Rate Arrangements for NAFTA," IMF Discussion Paper No. WP/93/20, March.

Bayoumi, Tamim, and Barry Eichengreen, 1994, One Money or Many? Analyzing the Prospects for Monetary Unification in Various Parts of the World, Princeton Studies in International Finance no. 76, September, Princeton.

Bayoumi, Tamim, and Barry Eichengreen, 1996, "Optimum Currency Areas and Exchange Rate Volatility: Theory and Evidence Compared" January.

Cohen, Daniel, and Charles Wyplosz, 1989, "The European Monetary Union: An Agnostic Evaluation," in R. Bryant, D. Currie, J .Frenkel, P. Masson, and R. Portes, ed. Macroeconomic Policies in an Interdependent World, Washington DC, Brookings, 311-337. 
Commission of the European Communities, 1990, “One Market, One Money" European Economy no. 44, October.

De Grauwe, Paul, and Wim Vanhaverbeke, 1993, "Is Europe an Optimum Currency Area? Evidence from Regional Data," in Policy Issues in the Operation of Currency Unions, edited by Paul Masson and Mark Taylor, Cambridge University Press.

Eichengreen, Barry, 1988, "Real Exchange Rate Behavior Under Alternative International Monetary Regimes: Interwar Evidence," European Economic Review 32, 363-371.

Eichengreen, Barry, 1992, "Should the Maastricht Treaty Be Saved?" Princeton Studies in International Finance, No. 74, International Finance Section, Princeton Univ., December.

Kenen, Peter, 1969, "The Theory of Optimum Currency Areas: An Eclectic View," in R. Mundell and A. Swoboda, eds., Monetary Problems in the International Economy, Chicago: University of Chicago Press.

Krugman, Paul, 1993, "Lessons of Massachusetts for EMU," in F. Giavazzi and F. Torres, eds., The Transition to Economic and Monetary Union in Europe, Cambridge University Press, New York, 241-261.

Lucas, Robert E. Jr., 1976, "Econometric Policy Evaluation: A Critique" in The Phillips Curve and Labor Markets (K. Brunner and A.H. Meltzer, eds.), Carnegie-Rochester Conference Series on Public Policy, North-Holland, Amsterdam, 19-46.

McKinnon, Ronald, 1963, “Optimum Currency Areas" American Economic Review, 53, September, 717-724. 
Mundell, Robert, 1961, "A Theory of Optimum Currency Areas", American Economic Review, November, 509-517.

Ricci, Luca A. (1996) "Exchange Rate Regimes and Location" Konstanz University mimeo.

Stockman, Alan, 1988, "Sectoral and National Aggregate Disturbances to Industrial Output in Seven European Countries," Journal of Monetary Economics 21-2/3, 387-409.

Tavlas, George, 1992, "The 'New' Theory of Optimal Currency Areas," International Monetary Fund, Washington, DC.

Weber, Axel, 1991, "EMU and Asymmetries and Adjustment Problems in the EMS-Some Empirical Evidence," European Economy, 1, 187-207. 
Extent of International Trade

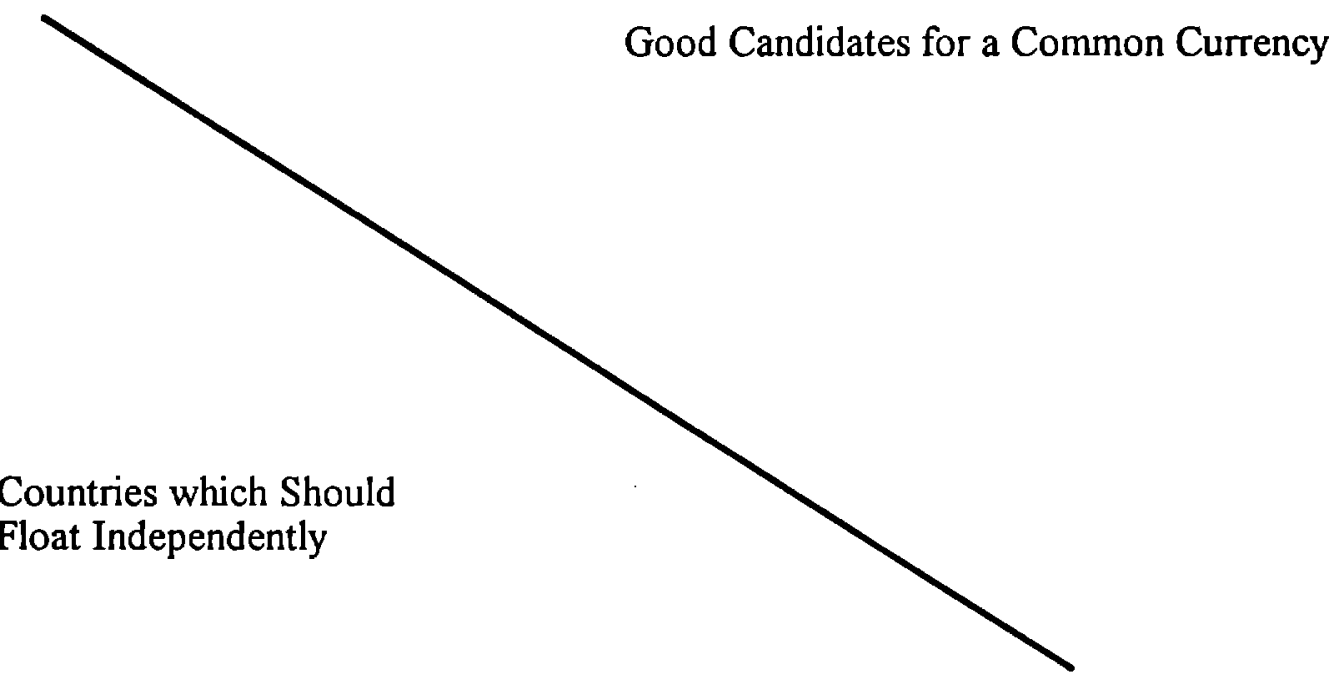

Correlation of Business Cycles Across Countries

Figure 1 




Figure 2



Figure 3 


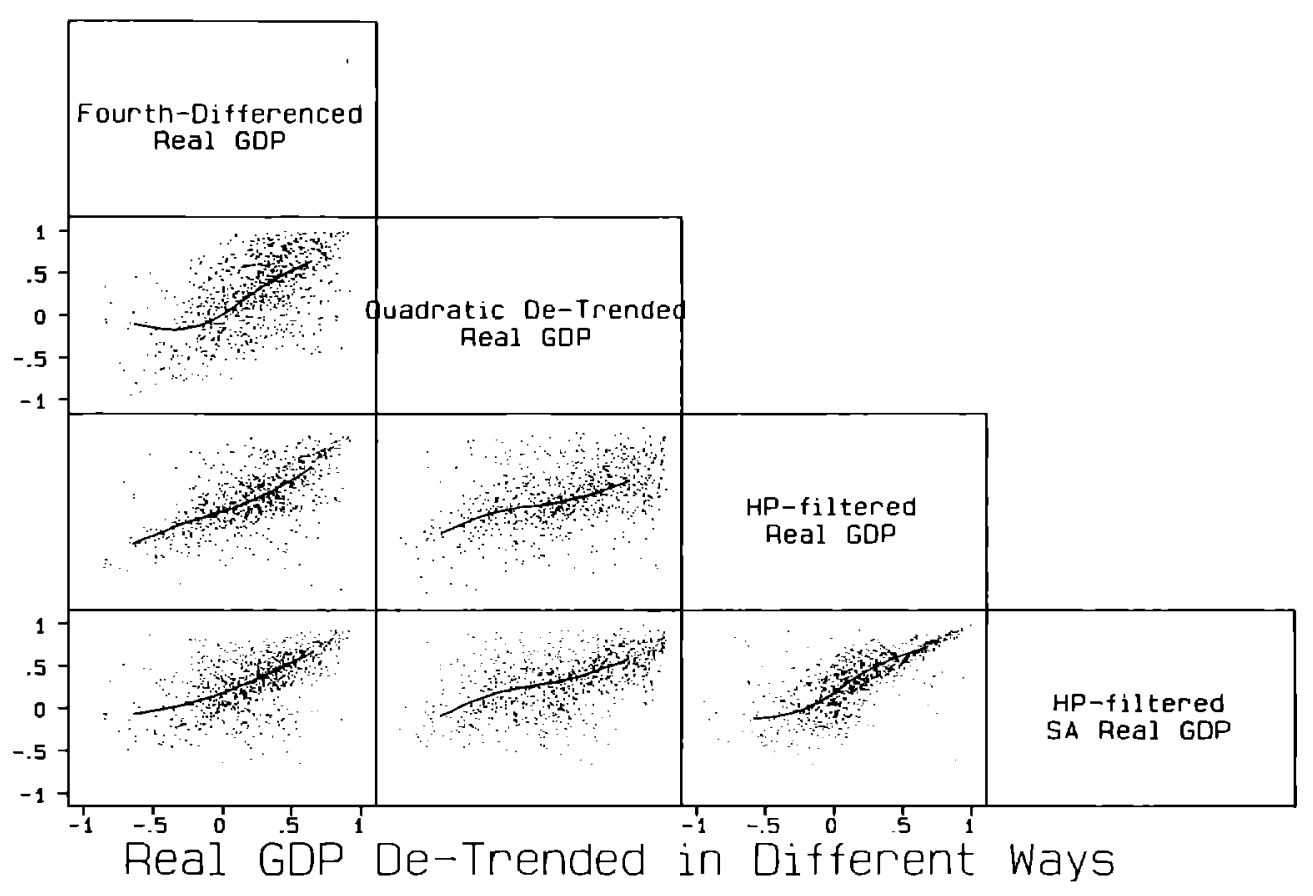

Figure 4 